Research Paper

\title{
Survival and Quality of Life Benefit after Endoscopic Management of Malignant Central Airway Obstruction
}

\author{
Grigoris Stratakos ${ }^{1}$, Vasiliki Gerovasili2 ${ }^{2}$ Charalampos Dimitropoulos' ${ }^{1}$, Ioannis Giozos ${ }^{3}$, Filippos T. \\ Filippidis², Sofia Gennimata ${ }^{1}$, Paul Zarogoulidis ${ }^{4}{ }^{\bowtie}$, Athanasios Zissimopoulos ${ }^{5}$, Athanasia Pataka ${ }^{4}$, Nikos \\ Koufos ${ }^{1}$, Spyros Zakynthinos ${ }^{2}$, Konstantinos Syrigos ${ }^{3}$, Nikos Koulouris ${ }^{1}$ \\ 1. 1st Pulmonary Medicine Department of National and Kapodistrian University of Athens, "Sotiria" General Hospital Athens, Greece; \\ 2. 1st Respiratory and Critical Care Medicine department of National and Kapodistrian University of Athens, "Evangelismos" Hospital Athens, Greece; \\ 3. Oncology Unit, 3rd Department of Internal Medicine of National and Kapodistrian University of Athens, "Sotiria" General Hospital, Athens, Greece; \\ 4. Pulmonary Oncology Unit, "G. Papanikolaou" General Hospital, Aristotle University of Thessaloniki, Thessaloniki, Greece; \\ 5. Nuclear Medicine Department, University General Hospital of Alexandroupolis, Democritus University of Thrace, Alexandroupolis, Greece. \\ $\square$ Corresponding author: Paul Zarogoulidis, M.D, PhD. Pulmonary Department-Oncology Unit, “G. Papanikolaou” General Hospital, Aristotle University of \\ Thessaloniki, Thessaloniki, Greece. Fax: 00302310992424 Mobile: 00306977271974 E-mail: pzarog@hotmail.com.
}

() Ivyspring International Publisher. Reproduction is permitted for personal, noncommercial use, provided that the article is in whole, unmodified, and properly cited. See http://ivyspring.com/terms for terms and conditions.

Received: 2016.01.26; Accepted: 2016.03.21; Published: 2016.04.25

\begin{abstract}
Background: Although interventional management of malignant central airway obstruction (mCAO) is well established, its impact on survival and quality of life (QoL) has not been extensively studied.

Aim: We prospectively assessed survival, QoL and dyspnea (using validated EORTC questionnaire) in patients with mCAO 1 day before interventional bronchoscopy, 1 week after and every following month, in comparison to patients who declined this approach.

Material/Patients/Methods: 36 patients underwent extensive interventional bronchoscopic management as indicated, whereas 12 declined. All patients received full chemotherapy and radiotherapy as indicated. Patients of the 2 groups were matched for age, comorbidities, type of malignancy and level of obstruction. Follow up time was 8.0 \pm 8.7 (range 1-38) months.

Results: Mean survival for intervention and control group was $10 \pm 9$ and $4 \pm 3$ months respectively $(p=0.04)$. QoL improved significantly in intervention group patients up to the $6^{\text {th }}$ month $(p<0.05)$ not deteriorating for those surviving up to 12 months. Dyspnea decreased in patients of the intervention group 1 month post procedure remaining reduced for survivors over the 12th month. Patients of the control group had worse QoL and dyspnea in all time points.

Conclusions: Interventional management of patients with $\mathrm{mCAO}$, may achieve prolonged survival with sustained significant improvement of QoL and dyspnea.
\end{abstract}

Key words: lung cancer, intervention, quality of life.

\section{Introduction}

Malignant tumors may produce central airway obstruction (CAO) causing severe dyspnea, significant morbidity and mortality.[1] Lung cancer patients develop CAO in as much as $30 \%$ of cases while up to $40 \%$ of the deaths are attributed to loco-regional progression.[2] Chemo- and radio-therapy alone, seldom can alleviate airway obstruction due to non-small cell lung cancer (NSCLC). Most patients present at advanced stage while surgical interventions are rarely indicated for tumors of the trachea and main carina. In these cases, interventional therapeutic bronchoscopy remains an important alternative method for airway management.[3-5]

Reported survival of patients with untreated malignant CAO usually ranges from 1 - 2 months with many of them dying of asphyxia or on mechanical ventilation.[6] Although the palliative effect of 
endoscopic management of mCAO is well established[7], the long-term effect of these techniques has seldom been examined in terms of quality of life (QoL) and survival. Several authors have argued that temporary relief of dyspnea may lead to prolonged suffering from the patient's point of view.[8] It is therefore necessary to elucidate whether there is a clear QoL and survival benefit after interventional management in patients with inoperable malignant CAO.

Main reasons for lack of prospective, controlled studies on survival and QoL should be methodological and ethical issues. Most studies investigate partially dyspnea and performance status scores but not overall QoL.[9-18] To the authors' knowledge there are only two prospective studies regarding multimodality approach in malignant CAO that include QoL questionnaires but without comparing the results to standard oncologic treatment nor elucidating the impact on survival or QoL.[19-21]

Our aim was to prospectively assess the effect of interventional bronchoscopic procedures when added to the standard oncologic treatment, in patients with inoperable mCAO. Primary objectives included assessment of dyspnea and overall QoL, as well as survival, in comparison to patients who declined interventional management and thus acted as control group. Secondary objective was to identify pre-procedural clinical, radiological or endoscopic characteristics which might correlate with poor post-procedural outcome. We hypothesized that re-establishing airway patency in symptomatic patients with inoperable mCAO would result in substantial symptomatic relief, improved QoL and increased survival.

\section{Methods}

\section{Study Design}

This is a prospective study performed over a 3 years period at a University Hospital. Approval was obtained from the Hospital's ethical committee and patients gave signed informed consent before enrolment. Patients declining interventional management were also evaluated and formed the control group.

\section{Subjects}

All consecutive patients symptomatic due to inoperable malignant $\mathrm{CAO}$, other than small cell lung cancer, were initially evaluated with thorax CT and video-bronchoscopy. Indication for interventional management was considered after interdisciplinary counselling with interventional pulmonologist, thoracic surgeon and oncologist. Patients were excluded if other medical conditions could be responsible for the symptoms, if they had irreversible bleeding diathesis, severe cardiopulmonary compromise or inability to tolerate bronchoscopy. The patients underwent bronchoscopic recanalization of the airway (Intervention group) and subsequently followed standard oncologic chemo-radio therapy, according to international guidelines. If the patients, for any reason, declined the interventional approach, then sole standard oncologic management with chemo-radio therapy was offered (Control group). All patients were followed for QoL and performance status every month up to their death.

\section{Interventional Bronchoscopic procedures}

Both flexible and rigid bronchoscopy were used, applying all available in our institution interventional modalities (namely electro-cryotherapy, rigid bronchoscopy and stent placement), according to the specific situation and the published evidence.[1, 4, 5] The procedure was considered successful when complete re-establishment of the airway patency was achieved with post-intervention lumen $80-100 \%$ of normal width. Partially successful if the post-intervention patency was $50-80 \%$, and unsuccessful if the patency remained less than $50 \%$ of normal width. In case of relapse of the stenosis and worsening of the symptoms during follow up, interventional bronchoscopy was repeatedly performed as needed to re-establish patency.

\section{QoL and Symptom assessment}

All patients were assessed before enrolment with the Eastern Cooperative Oncology Group (ECOG) score for the performance status while dyspnea and QoL were assessed with the European Organization for Research and Treatment of Cancer Quality of Life Questionnaire (EORTC QLQ-C30) being the most frequently used and well documented in European countries and validated in Greek language.[22-27] EORTC QLQ-C30 consists of five functional and three symptom scales, as well as a specific lung component with 15 questions assessing respiratory symptoms in detail. Dyspnea is assessed both by the overall questionnaire and the lung component questions (LC dyspnea). The initial evaluation was followed by an assessment 1 week after establishment of airway patency for the intervention group and then every following month for both groups until eventual death of the patients.

\section{Statistical Analysis}

All continuous variables are presented by mean \pm SD. Normality of distribution was checked by Kolmogorof-Smirnof test. Continuous variables were compared by unpaired Student's t-test or Mann-Whitney U test when appropriate. Qualitative 
variables were compared by $\chi^{2}$ or Fisher exact test. The within-patient changes of the intervention group before and after the intervention were evaluated with paired t-test or paired Wilcoxon test when appropriate. Within-patient changes in both groups were analyzed using Linear Mixed Effects (LME) Modeling.

Kaplan-Meier method was used to compare survival between intervention and control group. Survival time was defined as time from the endoscopic diagnosis of inoperable malignant CAO until death. The two groups were compared using the log-rank test. The direct effect of the intervention upon overall patient survival was analyzed and quantified through Cox Proportional Hazards modeling. P values $<0.05$ were considered significant.

\section{Results}

During the 3 years study period 53 patients were enrolled in the study. Two subjects were excluded because after interventional bronchoscopic management, they qualified for curative surgical treatment. 5 patients presenting with metastatic extra-thoracic malignancy were analyzed separately. Thus the final analysis was performed on 46 patients (38 males) aged $66 \pm 11$ years.

Thirty-four patients with NSCLC underwent extensive interventional bronchoscopic management as indicated (intervention group), whereas 12 declined endoscopic treatment (control group) (Table 1). Patients of the 2 groups did not statistically differ in terms of age, gender, type or stage of malignancy and presence of atelectasis, time between diagnosis and enrollment (Table 1). There was a difference regarding the level of obstruction, which in the intervention group patients was more often located centrally than in the patients of the control group. Diagnosis of COPD was less often reported in the intervention group, although in this group dyspnea severity was worse.

Following intervention $(n=34)$, most patients had an improvement in their airway diameter. 14 patients (41\%) were considered to have had a successful procedure, 17 patients $(50 \%)$ had only partially successful procedure and in 3 patients $(8.8 \%)$ the procedure was considered unsuccessful. Nine patients underwent retreatment after $5 \pm 4$ (range 1-11) months.

Overall follow up time was $8.6 \pm 8.5$ (range 1-43) months. Seven patients are still alive (5 in the intervention group and 2 in the control group) followed for $14 \pm 16$ (range 1-43) months. Mean survival time for intervention and control group was $10 \pm 9$ and $4 \pm 3$ months, respectively (log rank $p=0.005$ ) (Figure 1). The hazard ratio was modeled through cox proportion hazards modeling where it was observed that the death hazard increases by 2,93 times without interventional management of $\mathrm{CAO}(\mathrm{p}=0.009)$.

Table 1. Baseline characteristics of the patients.

\begin{tabular}{|c|c|c|c|}
\hline & $\begin{array}{l}\text { Intervention } \\
\text { Group }(\mathrm{n}=34)\end{array}$ & $\begin{array}{l}\text { Control Group } \\
(\mathrm{n}=12)\end{array}$ & $\mathrm{p}$ \\
\hline Age (years) & $65 \pm 12$ & $66 \pm 8$ & 0,96 \\
\hline \multicolumn{4}{|l|}{ Gender n, $(\%)$} \\
\hline male & $27(79,4 \%)$ & $11(91,7 \%)$ & \multirow{2}{*}{0,66} \\
\hline female & $7(20,6 \%)$ & $1(8,3 \%)$ & \\
\hline \multicolumn{4}{|l|}{ Comorbidities $\mathrm{n},(\%)$} \\
\hline yes & $20(58,8 \%)$ & $10(83,3 \%)$ & \multirow[t]{2}{*}{0,17} \\
\hline no & $14(41,2 \%)$ & $2(16,7 \%)$ & \\
\hline \multicolumn{4}{|l|}{ COPD } \\
\hline yes & $8(23,5 \%)$ & $8(66,7 \%)$ & \multirow[t]{2}{*}{0,013} \\
\hline no & $26(76,5 \%)$ & $4(33,3 \%)$ & \\
\hline \multicolumn{4}{|l|}{ CHF } \\
\hline yes & $6(17,6 \%)$ & $2(16,7 \%)$ & \multirow[t]{2}{*}{1,00} \\
\hline no & $28(82,4 \%)$ & $10(83,3 \%)$ & \\
\hline \multicolumn{4}{|l|}{ ICD } \\
\hline yes & $8(23,5 \%)$ & $3(25 \%)$ & \multirow[t]{2}{*}{1} \\
\hline no & $26(76,5 \%)$ & $9(75 \%)$ & \\
\hline \multicolumn{4}{|c|}{ Long term oxygen therapy } \\
\hline yes & $11(32,4 \%)$ & $3(25 \%)$ & \multirow[t]{2}{*}{0,72} \\
\hline no & $23(67,6 \%)$ & $9(75 \%)$ & \\
\hline \multicolumn{4}{|c|}{$\begin{array}{l}\text { Histotype of Lung Cancer } \\
\text { Malignancy } n,(\%)\end{array}$} \\
\hline squamous & $25(75,8 \%)$ & $8(66,7 \%)$ & \multirow[t]{5}{*}{0,76} \\
\hline adenocarcinoma & $5(15,2 \%)$ & $3(25 \%)$ & \\
\hline large cell carcinoma & $1(3 \%)$ & 0 & \\
\hline non differentiated & $1(3 \%)$ & $1(8,3 \%)$ & \\
\hline other & $1(3 \%)$ & 0 & \\
\hline \multicolumn{4}{|c|}{ Stage of Malignancy n,(\%) } \\
\hline $\mathrm{T} 3$ & $9(26,5 \%)$ & $1(8,3 \%)$ & \multirow[t]{3}{*}{0,41} \\
\hline $\mathrm{T} 4$ & $25(73,5 \%)$ & $11(91,7 \%)$ & \\
\hline No & $2(5,9 \%)$ & $0(0 \%)$ & \\
\hline N1 & $4(11,8 \%)$ & $3(25 \%)$ & \multirow[t]{3}{*}{0,50} \\
\hline N2 & $18(52,9 \%)$ & $7(58,3 \%)$ & \\
\hline N3 & $10(29,4 \%)$ & $2(16,7 \%)$ & \\
\hline M0 & $24(70,6 \%)$ & $5(41,7 \%)$ & \multirow[t]{2}{*}{0,09} \\
\hline M1 & $10(29,4 \%)$ & $7(58,3 \%)$ & \\
\hline \multicolumn{4}{|l|}{ Atelectasis $\mathrm{n},(\%)$} \\
\hline yes & $16(48,5 \%)$ & $9(75 \%)$ & \multirow[t]{2}{*}{0,17} \\
\hline no & $17(51,5 \%)$ & $3(25 \%)$ & \\
\hline \multicolumn{4}{|c|}{ Level of Obstruction n, $(\%)$} \\
\hline trachea & $28(52,9 \%)$ & $1(8,3 \%)$ & \multirow[t]{3}{*}{$<0.001$} \\
\hline main stem & $15(44,1 \%)$ & $6(50 \%)$ & \\
\hline lobar bronchi & $1(2,9 \%)$ & $5(41,7 \%)$ & \\
\hline ECOG score & $2.7 \pm 1$ & $2 \pm 1.3$ & 0,1 \\
\hline Global Health & $42 \pm 28$ & $44 \pm 28$ & 0,8 \\
\hline Physical Function & $41 \pm 29$ & $51 \pm 29$ & 0,29 \\
\hline Dyspnea & $79 \pm 26$ & $53 \pm 30$ & 0,005 \\
\hline LC dyspnea & $66 \pm 30$ & $50 \pm 33$ & 0,13 \\
\hline LC coughing & $66 \pm 30$ & $61 \pm 24$ & 0,64 \\
\hline LC Hemoptysis & $33 \pm 29$ & $22 \pm 29$ & 0,26 \\
\hline
\end{tabular}




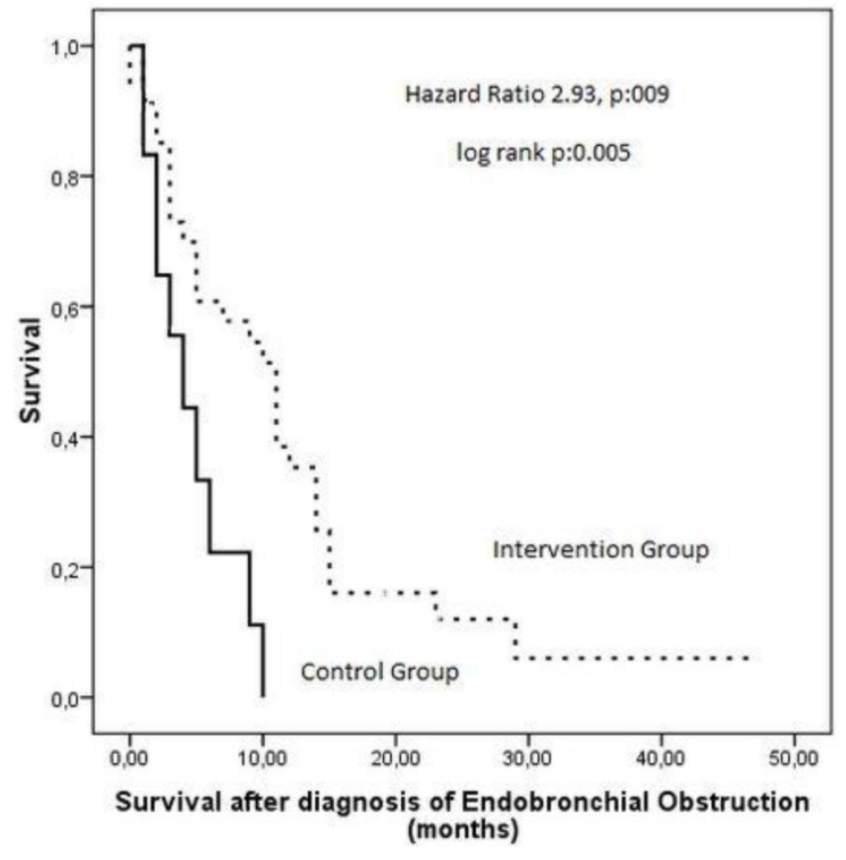

Figure 1. Kaplan Meier curves showing survival after diagnosis of airway obstruction in patients of the intervention group as compared to the control group.

As shown in Table 2, global health EORTC scores compared with pre-intervention values, significantly improved in all patients of the intervention group one week post intervention and remained improved up to the $3^{\text {rd }}$ month, in all surviving patients $(n=26)$ $(p<0.05)$. EORTC scores did not deteriorate in patients surviving up to 12 months after the intervention $(n=9)$ as compared to one week post intervention values $(p>0.05)$. Dyspnea significantly decreased in all surviving patients of the intervention group one month after the procedure $(n=34)(p<0.05)$. For those surviving over the $6^{\text {th }}(n=19)$ and over the $15^{\text {th }}(n=6)$ month dyspnea remained significantly improved $(p<0.05)$. Physical function immediately improved post intervention remaining high even 12 months post intervention for surviving patients $(p<0.05)$. Coughing and hemoptysis decreased significantly in intervention group patients remaining low, up to the $9^{\text {th }}$ month (Table 2).

Regarding pre-intervention patient characteristics, patients initially presenting with atelectasis had greater and sustained improvement in EORTC global health component at 1 month compared to those without atelectasis $(+26.1 \pm 29.3$ vs $3.3 \pm 30.6 ; \quad \mathrm{p}=0.047)$. All other pre-intervention parameters (age, gender, type of malignancy, level of $\mathrm{CAO}$, metastases or co-morbidities, LTOT, previous chemo- radio therapy, base line EORTC assessment) did not significantly influence outcomes.

Between the $1^{\text {st }}$ and the $6^{\text {th }}$ month post intervention, control group patients had significantly lower quality of life $(\mathrm{p}<0.05)$ and higher dyspnea $(\mathrm{p}<0.05)$ (Figure 2, Table 3). After $6^{\text {th }}$ month, not enough control group patients were alive to conduct comparative analysis.

Linear Mixed-effects Modeling was performed for both groups to confidently model the patient's course through time as described by specific parameters. The parameters analyzed were Global QoL, Physical Function, Dyspnea, LC-Dyspnea, LC-Cough and LC-Haemoptysis. The Intervention-Group was modeled from 1 week after the intervention onwards while the control group was modeled from the whole dataset (Table 4). Global QoL parameter reveals that, although control group patients had significantly lower QoL, rates of deterioration for the two groups did not differ significantly $(-3,26$ vs $-2,07)$. Regarding the 'Physical Function' parameter, the intervention group patients deteriorate at a slower rate than those of the control group $(-2,89$ vs $-1,47)$ while regarding the 'Dyspnea' parameter, the intervention group patients deteriorate at a much slower rate than those of the control group (2,73 vs 4,34 respectively for overall dyspnea and 2,96 vs 2,04 for LC dyspnea). 'LC-Cough' \& 'LC-Haemoptysis' did not present a linear pattern versus time, adequate for this analysis.

Table 2. ECOG scores and the QoL, physical function, dyspnea, LC dyspnea, LC coughing and LC hemoptysis values of the EORTC questionnaire in the surviving patients of the intervention group up to 18 months post intervention.

\begin{tabular}{|c|c|c|c|c|c|c|c|c|c|}
\hline & $\begin{array}{l}\text { pre intervention } \\
\text { value }(n=34)\end{array}$ & $\begin{array}{l}\text { post } 1 \\
\text { week } \\
(\mathrm{n}=34)\end{array}$ & $\begin{array}{l}\text { post } 1 \\
\text { month } \\
(\mathrm{n}=34)\end{array}$ & $\begin{array}{l}\text { post } 3 \\
\text { months } \\
(\mathrm{n}=26)\end{array}$ & $\begin{array}{l}\text { post } 6 \\
\text { months } \\
(\mathrm{n}=19)\end{array}$ & $\begin{array}{l}\text { post } 9 \\
\text { months } \\
(n=16)\end{array}$ & $\begin{array}{l}\text { post } 12 \\
\text { months }(n=9)\end{array}$ & $\begin{array}{l}\text { post } 15 \\
\text { months } \\
(n=6)\end{array}$ & $\begin{array}{l}\text { post } 18 \\
\text { months } \\
(\mathrm{n}=3)\end{array}$ \\
\hline ECOG & $2.7 \pm 1$ & $2 \pm 1.4^{*}$ & $2.4 \pm 1.3^{*}$ & $2.3 \pm 1.5$ & $2.1 \pm 1.5$ & $2.3 \pm 1.5$ & $1.4 \pm 1.1^{*}$ & $2.5 \pm 1.5$ & $2 \pm 1$ \\
\hline Global Health & $42 \pm 28$ & $64 \pm 18^{*}$ & $57 \pm 20^{*}$ & $57 \pm 26^{*}$ & $62 \pm 21$ & $48 \pm 32$ & $57 \pm 24$ & $60 \pm 21$ & $47 \pm 19$ \\
\hline Physical Function & $41 \pm 29$ & $55 \pm 32^{*}$ & $55 \pm 31^{*}$ & $57 \pm 36^{*}$ & $63 \pm 30$ & $49 \pm 34$ & $67 \pm 22^{*}$ & $54 \pm 20$ & $51 \pm 31$ \\
\hline Dyspnea & $79 \pm 26$ & $35 \pm 34^{*}$ & $39 \pm 37^{*}$ & $45 \pm 36^{*}$ & $37 \pm 37^{*}$ & $47 \pm 41^{*}$ & $41 \pm 22^{*}$ & $39 \pm 39^{*}$ & $67 \pm 58$ \\
\hline LC dyspnea & $66 \pm 30$ & $33 \pm 27^{*}$ & $35 \pm 29^{*}$ & $33 \pm 34^{*}$ & $32 \pm 24^{*}$ & $50 \pm 37$ & $41 \pm 17$ * & $41 \pm 33$ & $50 \pm 35$ \\
\hline LC coughing & $66 \pm 30$ & $42 \pm 29^{*}$ & $42 \pm 37^{*}$ & $42 \pm 30^{*}$ & $31 \pm 25^{*}$ & $40 \pm 38^{*}$ & $37 \pm 35$ & $49 \pm 35$ & $22 \pm 38$ \\
\hline LC Hemoptysis & $33 \pm 29$ & $15 \pm 19^{*}$ & $12 \pm 22^{*}$ & $10 \pm 19^{*}$ & $31 \pm 25$ & $18 \pm 25$ * & $11 \pm 17^{*}$ & $22 \pm 27$ & $11 \pm 19$ \\
\hline
\end{tabular}

ECOG: Eastern Cooperative Oncology Group, LC: lung component, values are expressed as mean \pm SD, * significant compared to pre-intervention values. 

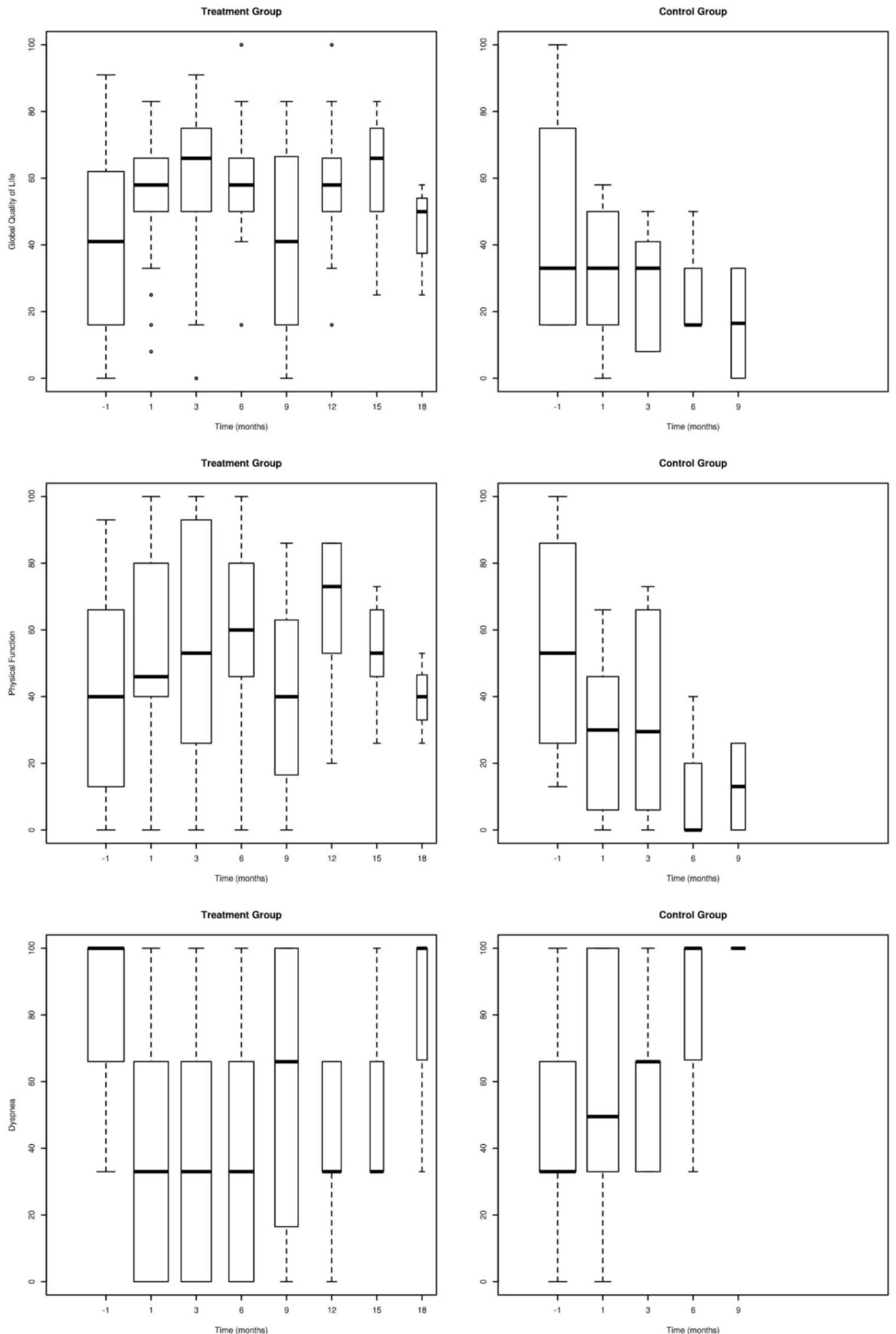

Figure 2. Global QoL (QL2), Physical function (PF2) and Level of Dyspnea (DY) assessed with the EORTC questionnaire in patients of the intervention group in comparison to the control group. (Error bars represent mean $\pm 2 \mathrm{SE}$ ). 
Table 3. Comparison of the two groups at base line and during follow up to 6 months.

\begin{tabular}{|c|c|c|c|c|}
\hline & Baseline & Post 1 month & 3months & 6months \\
\hline \multicolumn{5}{|l|}{ Global Health } \\
\hline Intervention Group & $42 \pm 28(n=34)$ & $57 \pm 21(n=31)$ & $57 \pm 26(n=23)$ & $62 \pm 21(n=17)$ \\
\hline Control Group & $44 \pm 28(n=12)$ & $30 \pm 21(n=10)^{*}$ & $29 \pm 17(n=6)^{*}$ & $28 \pm 19(n=3)^{*}$ \\
\hline \multicolumn{5}{|l|}{ Physical Function } \\
\hline Intervention Group & $41 \pm 29(n=34)$ & $55 \pm 31(n=31)$ & $57 \pm 36(n=23)$ & $63 \pm 30(n=17)$ \\
\hline Control group & $51 \pm 29(n=12)$ & $29 \pm 24(n=10)^{*}$ & $34 \pm 32(n=6)^{*}$ & $13 \pm 23(n=3)^{*}$ \\
\hline \multicolumn{5}{|l|}{ Dyspnea } \\
\hline Intervention Group & $79 \pm 26(n=34)$ & $39 \pm 37(n=31)$ & $45 \pm 36(n=23)$ & $37 \pm 37(n=17)$ \\
\hline Control Group & $53 \pm 30(n=12)^{*}$ & $57 \pm 35(n=10)^{*}$ & $61 \pm 25(n=6)^{*}$ & $78 \pm 38(n=3)^{*}$ \\
\hline \multicolumn{5}{|l|}{ LC dyspnea } \\
\hline Intervention Group & $66 \pm 30(n=34)$ & $35 \pm 29(n=31)$ & $33 \pm 34(n=23)$ & $32 \pm 25(n=17)$ \\
\hline Control Group & $50 \pm 33(n=12)$ & $65 \pm 27(n=10)^{*}$ & $70 \pm 31(n=6)^{*}$ & $78 \pm 11(n=3)^{*}$ \\
\hline \multicolumn{5}{|l|}{ LC coughing } \\
\hline Intervention Group & $66 \pm 30(n=34)$ & $42 \pm 37(n=31)$ & $42 \pm 31(n=23)$ & $31 \pm 25(n=17)$ \\
\hline Control Group & $61 \pm 24(n=12)$ & $57 \pm 32(n=10)$ & $44 \pm 17(n=6)$ & $11 \pm 19(n=3)$ \\
\hline \multicolumn{5}{|l|}{ LC Hemoptysis } \\
\hline Intervention Group & $33 \pm 29(n=34)$ & $12 \pm 22(n=31)$ & $10 \pm 19(n=25)$ & $6 \pm 13(n=17)$ \\
\hline Control Group & $22 \pm 29(\mathrm{n}=12)$ & $13 \pm 17(n=10)$ & $11 \pm 17(n=6)$ & $44 \pm 51(n=3)$ \\
\hline
\end{tabular}

LC Lung Component, *significantly different when compared to intervention group.

Table 4. Linear Mixed-Effects (LME) Analysis of the intervention and control groups for specific parameters.

\begin{tabular}{|c|c|c|c|c|c|c|c|}
\hline & \multicolumn{3}{|c|}{ Intervention Group } & \multicolumn{4}{|c|}{ Control Group } \\
\hline & Intercept & Coefficient & P-value & $\begin{array}{l}\text { Time to Intervention Group } \\
\text { Initial Values (months) }\end{array}$ & Intercept & Coefficient & P-value \\
\hline Global Health & 62,21 & $-3,26$ & $<0.001$ & 6,87 & 29,53 & $-2,07$ & 0,057 \\
\hline Physical Function & 56,53 & $-2,89$ & 0.001 & 5,21 & 29,92 & $-1,47$ & 0,466 \\
\hline Dyspnea & 35,37 & 2,73 & 0,007 & 21,17 & 53,86 & 4,34 & 0,006 \\
\hline LC-Dyspnea & 29,91 & 2,96 & 0.001 & 12,49 & 69,09 & 2,04 & 0,072 \\
\hline LC-Cough & 38,74 & 0,65 & 0,408 & NA & 67,83 & $-6,77$ & 0,007 \\
\hline LC-Haemoptysis & 10,83 & 0,09 & 0,761 & NA & 6,37 & 3,39 & 0,303 \\
\hline
\end{tabular}

LME analysis was performed in order to confidently quantify the patients' course over time as described by each parameter. Intercepts and coefficients are characteristics of the linear models. Intercepts indicate the value of each parameter at Time $=0$. Coefficients are an indication of the rate of change of each parameter as time passes on a monthly basis. The p-values indicate the validity of the modelling. "Time to Intervention-Group Initial Values" parameter indicates the time lapse in months as calculated by the linear model, until the intervention group patients reached the pre-intervention values; hence it is an indication of the time 'gained' by the patients in terms of quality of life, dyspnea severity etc. and was calculated only for the parameters having a statistically significant linear model.

\section{Discussion}

Patients with advanced NSLC and CAO have poor prognosis and left untreated their survival usually does not exceed few weeks. ${ }^{6}$ Although therapeutic bronchoscopy has been previously reported to relieve symptoms of cough, dyspnea and hemoptysis, achieving endoscopic, radiologic, spirometric and QoL improvements, it is generally considered as a palliative measure not able to essentially prolong patients' survival.[8, 17-21]

The present prospective study provided detailed assessment of the impact of interventional bronchoscopy in patients with inoperable malignant $\mathrm{CAO}$ versus matched patients undergoing only standard oncologic treatment. Using a validated tool we were able to assess symptoms, overall and respiratory specific QoL as well as long term survival of these patients. The results demonstrate that interventional approach may achieve significant and sustained QoL and dyspnea improvement together with prolonged survival in patients with airway obstructing malignancies.
In previous studies assessing the impact of bronchoscopic treatment in patients with inoperable malignant $\mathrm{CAO}$, either only one bronchoscopic modality was studied each time or no other systemic therapy towards their malignancy was administered.[6, 17, 20] However, interventional bronchoscopy using all available modalities together, may serve as a bridge to radiation and/or chemotherapy, allowing for a durable relief of symptoms.[11] All our patients improved clinically after the intervention and were able to sustain further oncologic treatment while two subjects even qualified for curative surgical treatment.

In our study cohort although all patients were offered the option of therapeutic bronchoscopy after interdisciplinary counseling several declined bronchoscopic treatment. These were patients with more distal level of obstruction, higher prevalence of COPD and lower grade of dyspnea according to the general component of the EORTC questionnaire. We hypothesize that prior dealing with COPD symptoms in combination with fear of complications, given their 
lower level of dyspnea, and less prominent obstructive symptoms was the main drawback of these patients to accept bronchoscopic treatment.

A limitation of our study is the small population rendering subgroup analysis limited albeit useful for generating hypotheses. Furthermore, the results of the QoL questionnaire were not correlated with objective respiratory functional testing. This would have been quite demanding given the advanced disease and the level of dyspnea of most patients.

There are several potential explanations of the survival benefit observed in our patient population undergoing interventional management: Timely management of malignant CAO may prevent or delay lethal complications such as post-obstructive pneumonia, sepsis and respiratory insufficiency, thus allowing adjuvant chemotherapy and external beam radiation to prolong survival.[21] In our study, patients treated bronchoscopically survived more than twice as long as patients treated only by standard oncologic treatment.

In a recent study Oviat et al. showed significant improvement of 6 min walking distance, FEV1 and FVC, dyspnea and QoL scores by day 30 post-intervention, not being able whatsoever to report longer follow up of their patients.[19] Similarly, Amjadi et al. reported decreased dyspnea but not significant QoL benefit one month post-intervention ${ }^{20}$. However, in our study in which patients were meticulously followed up to their death, validated EORTC QLQ-C30 QoL questionnaire produced much more encouraging data.

Overall, dyspnea, significantly decreased one month post-intervention and as LME analysis reveals it would take approximately 21 months for the patients of the intervention group to reach their pre-intervention values. This is extremely considerable given that average survival time of the control group is only 4 months and that of the intervention group is approximately 10 months. This means that most of the patients of the intervention group do not survive long enough to experience dyspnea as severe as the one they experienced before the intervention. Equally important, 'Global Quality of Life' measurements of the intervention group significantly improved immediately after intervention, while deterioration rate remained close to the one of the control group. This is expected since the intervention of the current study is only a means to palliate symptoms and facilitate other applied therapeutic strategies. Additionally LME analysis revealed that it takes approximately 7 months for the intervention group patients to reach their pre-intervention 'Global Quality of Life' values. Finally, 'Physical Function' improved in all patients of the study group immediately after intervention. LME analysis reveals that the deterioration rate is lower in the intervention group and that it would take approximately 5 months for the patients of the intervention group to reach their pre-intervention values.

To our knowledge there are not any other data in the literature reporting dyspnea and QoL assessment for such a long follow up period compared or not to a control group. Subgroup analysis of the pre-procedural clinical, radiological and endoscopic characteristics revealed that QoL and Dyspnea improvement was greater in patients initially presenting with atelectasis. All other parameters did not significantly influence treatment outcomes.

Recent ACCP Lung Cancer Guidelines mention several interventional bronchoscopic modalities for palliation of dyspnea due to inoperable malignant CAO.[28] The results of the present prospective, controlled study confirm the considerable benefit of interventional bronchoscopic management of such patients and make an argument that patients with malignant CAO treated endoscopically have less dyspnea, better QoL, improved physical function and longer survival than patients with oncologic treatment alone. Combined interventional and oncologic treatment should be considered in any multidisciplinary cancer care program and offered to all patients with lung cancer and inoperable CAO, especially when post-obstructive atelectasis is present. Since such an approach is often limited by the lack of interventional equipment and skills, the urgent need for respiratory physicians' training in therapeutic bronchoscopy and development of interventional units is also highlighted.[29] (Figures 3-8) Additional treatment with radiotherapy could be used based on the patient performance status and local interventional prior or after stent placement-debulking.[30-36] Multimodality treatment is necessary for patients with central tumors

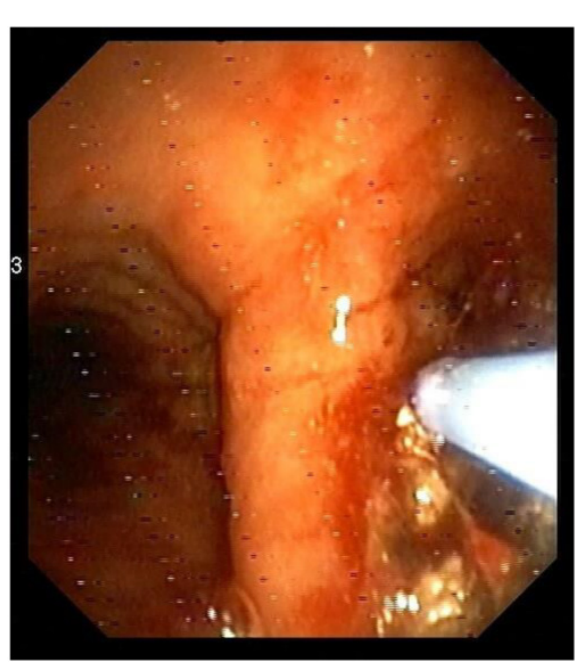
should be accompanied with systematic treatment when possible.

Figure 3. Argon Plasma Coagulation. 


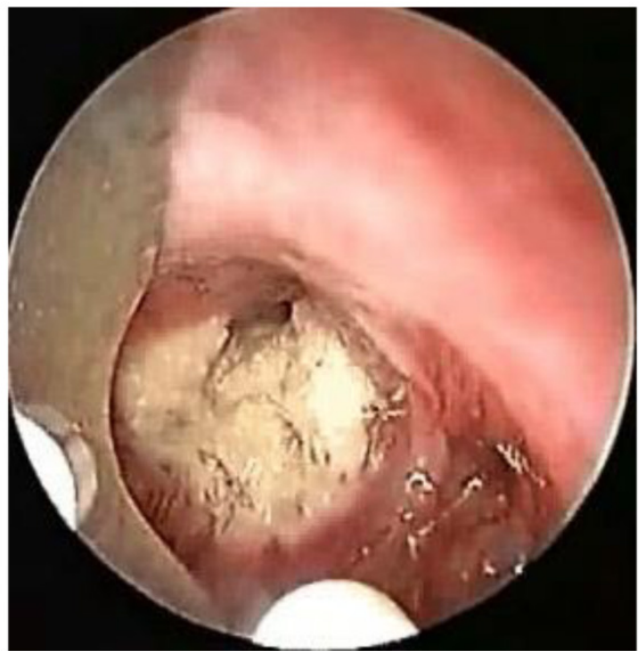

Figure 4. LASER beam coagulation.

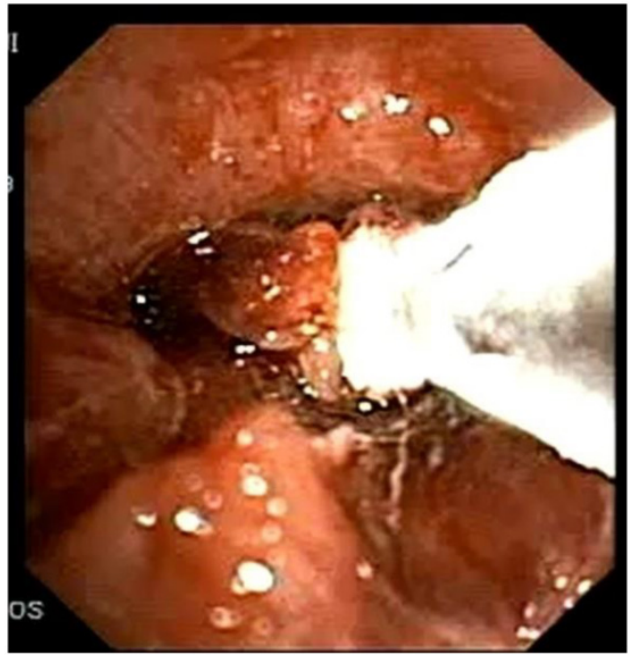

Figure 5. Cryoprobe performing debulking of central airways malignnat tumor.

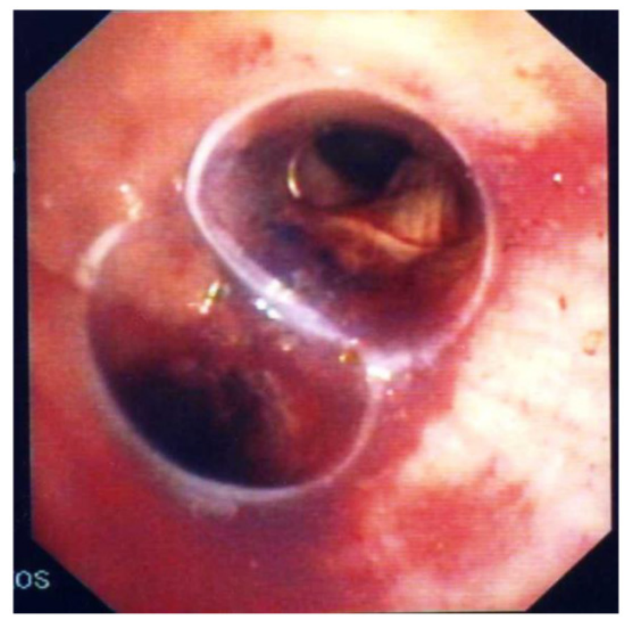

Figure 6. Bifurcated silicone stent.

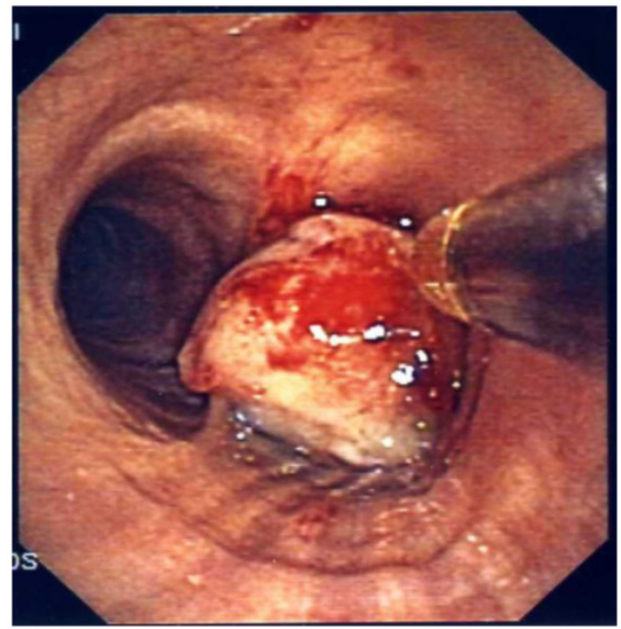

Figure 7. Rigid electrocatery.

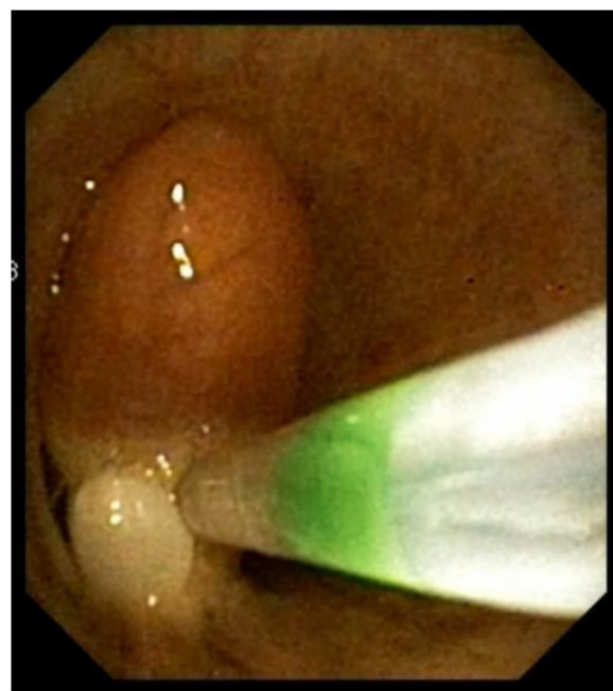

Figure 8. Removal of endobronchial tumor with loop.

\section{Acknowledgements}

We would like to cordially thank Research Scientist Dr K. Vougas, from the, Biomedical Research Foundation, Academy of Athens, Athens, Greece, for his valuable assistance in the statistical analysis and the presentation of the data of this study.

\section{Conflict of Interest}

None to declare.

\section{References}

1. Ernst A, Feller-Kopman D, Becker HD, Mehta AC. Central airway obstruction. American journal of respiratory and critical care medicine. 2004; 169: 1278-97. doi:10.1164/rccm.200210-1181SO.

2. Ginsberg R, Vokes EE. Ruben A. Non-small cell lung cancer. Cancer: principles and practice of oncology 5th Edn. Philadelphia: Lippincott-Raven. 1997: 858-911.

3. Chhajed PN, Baty F, Pless M, Somandin S, Tamm M, Brutsche MH. Outcome of treated advanced non-small cell lung cancer with and without central airway obstruction. Chest. 2006; 130: 1803-7. doi:10.1378/chest.130.6.1803. 
4. Lee P, Kupeli E, Mehta AC. Therapeutic bronchoscopy in lung cancer. Laser therapy, electrocautery, brachytherapy, stents, and photodynamic therapy. Clinics in chest medicine. 2002; 23: 241-56.

5. Bolliger CT, Sutedja TG, Strausz J, Freitag L. Therapeutic bronchoscopy with immediate effect: laser, electrocautery, argon plasma coagulation and stents. The European respiratory journal. 2006; 27: 1258-71. doi:10.1183/09031936.06.00013906.

6. Macha HN, Becker KO, Kemmer HP. Pattern of failure and survival in endobronchial laser resection. A matched pair study. Chest. 1994; 105: 1668-72.

7. Santos RS, Raftopoulos Y, Keenan RJ, Halal A, Maley RH, Landreneau RJ. Bronchoscopic palliation of primary lung cancer: single or multimodality therapy? Surgical endoscopy. 2004; 18: 931-6. doi:10.1007/s00464-003-9202-x.

8. Vonk-Noordegraaf A, Postmus PE, Sutedja TG. Tracheobronchial stenting in the terminal care of cancer patients with central airways obstruction. Chest. 2001; 120: 1811-4.

9. George PJ, Clarke G, Tolfree S, Garrett CP, Hetzel MR. Changes in regional ventilation and perfusion of the lung after endoscopic laser treatment. Thorax. 1990; 45: 248-53.

10. Saji H, Furukawa K, Tsutsui H, Tsuboi M, Ichinose S, Usuda J, et al. Outcomes of airway stenting for advanced lung cancer with central airway obstruction. Interactive cardiovascular and thoracic surgery. 2010; 11: 425-8. doi:10.1510/icvts.2010.238196.

11. Kim JH, Shin JH, Song HY, Ohm JY, Lee JM, Lee DH, et al. Palliative treatment of inoperable malignant tracheobronchial obstruction: temporary stenting combined with radiation therapy and/or chemotherapy. AJR American journal of roentgenology. 2009; 193: W38-42. doi:10.2214/AJR.08.2037.

12. Furukawa K, Ishida J, Yamaguchi G, Usuda J, Tsutsui H, Saito M, et al. The role of airway stent placement in the management of tracheobronchial stenosis caused by inoperable advanced lung cancer. Surgery today. 2010; 40: 315-20. doi:10.1007/s00595-008-4058-2.

13. Tanigawa N, Sawada S, Okuda Y, Kobayashi M, Mishima K. Symptomatic improvement in dyspnea following tracheobronchial metallic stenting for malignant airway obstruction. Acta radiologica. 2000; 41: 425-8.

14. Miyazawa T, Yamakido M, Ikeda S, Furukawa K, Takiguchi Y, Tada H, et al. Implantation of ultraflex nitinol stents in malignant tracheobronchial stenoses. Chest. 2000; 118: 959-65.

15. Husain SA, Finch D, Ahmed M, Morgan A, Hetzel MR. Long-term follow-up of ultraflex metallic stents in benign and malignant central airway obstruction. The Annals of thoracic surgery. 2007; 83: 1251-6. doi:10.1016/j.athoracsur.2006.11.066.

16. Breitenbucher A, Chhajed PN, Brutsche MH, Mordasini C, Schilter D, Tamm M. Long-term follow-up and survival after Ultraflex stent insertion in the management of complex malignant airway stenoses. Respiration; international review of thoracic diseases. 2008; 75: 443-9. doi:10.1159/000119053.

17. Chung FT, Chen HC, Chou CL, Yu CT, Kuo CH, Kuo HP, et al. An outcome analysis of self-expandable metallic stents in central airway obstruction: a cohort study. Journal of cardiothoracic surgery. 2011; 6: 46. doi:10.1186/1749-8090-6-46.

18. Mantovani G, Astara G, Manca G, Versace R, Contu P, Carai A. Endoscopic laser ablation as palliative treatment of endobronchial, nonresectable, or recurrent lung cancer: assessment of its impact on quality of life. Clinical lung cancer. 2000; 1: 277-85; discussion 86.

19. Oviatt PL, Stather DR, Michaud G, Maceachern P, Tremblay A. Exercise capacity, lung function, and quality of life after interventional bronchoscopy. Journal of thoracic oncology : official publication of the International Association for the Study of Lung Cancer. 2011; 6: 38-42. doi:10.1097/JTO.0b013e3181f8a298.

20. Amjadi K, Voduc N, Cruysberghs Y, Lemmens R, Fergusson DA, Doucette S, et al. Impact of interventional bronchoscopy on quality of life in malignant airway obstruction. Respiration; international review of thoracic diseases. 2008; 76: 421-8. doi:10.1159/000152832.

21. Razi SS, Lebovics RS, Schwartz G, Sancheti M, Belsley S, Connery CP, et al. Timely airway stenting improves survival in patients with malignant central airway obstruction. The Annals of thoracic surgery. 2010; 90: 1088-93. doi:10.1016/j.athoracsur.2010.06.093.

22. Oken MM, Creech RH, Tormey DC, Horton J, Davis TE, McFadden ET, et al. Toxicity and response criteria of the Eastern Cooperative Oncology Group. American journal of clinical oncology. 1982; 5: 649-55.

23. Montazeri A, Milroy R, Hole D, McEwen J, Gillis CR. Quality of life in lung cancer patients: as an important prognostic factor. Lung cancer. 2001; 31: $233-40$.

24. Montazeri A, Milroy R, Hole D, McEwen J, Gillis CR. How quality of life data contribute to our understanding of cancer patients' experiences? A study of patients with lung cancer. Quality of life research : an international journal of quality of life aspects of treatment, care and rehabilitation. 2003; 12: 157-66.

25. Aaronson NK, Ahmedzai S, Bergman B, Bullinger M, Cull A, Duez NI, et al. The European Organization for Research and Treatment of Cancer QLQ-C30: a quality-of-life instrument for use in international clinical trials in oncology. Journal of the National Cancer Institute. 1993; 85: 365-76.

26. Bergman B, Aaronson NK, Ahmedzai S, Kaasa S, Sullivan M. The EORTC QLQ-LC13: a modular supplement to the EORTC Core Quality of Life Questionnaire (QLQ-C30) for use in lung cancer clinical trials. EORTC Study Group on Quality of Life. European journal of cancer. 1994; 30A: 635-42.
27. Mystakidou K, Mendoza T, Tsilika E, Befon S, Parpa E, Bellos G, et al. Greek brief pain inventory: validation and utility in cancer pain. Oncology. 2001; 60: 35-42. doi:55294.

28. Kvale PA, Selecky PA, Prakash UB, American College of Chest P. Palliative care in lung cancer: ACCP evidence-based clinical practice guidelines (2nd edition). Chest. 2007; 132: 368S-403S. doi:10.1378/chest.07-1391.

29. McCaughan JS, Jr. Bronchoscopy in North America. The ACCP survey. Chest. 1992; 102: 1639; author reply 40

30. Simoff MJ. Endobronchial management of advanced lung cancer. Cancer control : journal of the Moffitt Cancer Center. 2001; 8: 337-43.

31. Hohenforst-Schmidt W, Zarogoulidis P, Pitsiou G, Linsmeier B, Tsavlis D, Kioumis I, et al. Drug Eluting Stents for Malignant Airway Obstruction: A Critical Review of the Literature. Journal of Cancer. 2016; 7: 377-90. doi:10.7150/jca.13611.

32. Hohenforst-Schmidt W, Linsmeier B, Zarogoulidis P, Freitag L, Darwiche K, Browning R, et al. Transtracheal single-point stent fixation in posttracheotomy tracheomalacia under cone-beam computer tomography guidance by transmural suturing with the Berci needle - a perspective on a new tool to avoid stent migration of Dumon stents. Therapeutics and clinical risk management. 2015; 11: 837-50. doi:10.2147/TCRM.S83230.

33. Walter RF, Zarogoulidis P, Mairinger FD, Werner R, Darwiche K, Zarogoulidis $\mathrm{K}$, et al. Cell viability of fibroblasts to pifenidone and sirolimus: a future concept for drug eluting stents. International journal of pharmaceutics. 2014; 466: 38-43. doi:10.1016/j.ijpharm.2014.03.003.

34. Zarogoulidis P, Darwiche K, Tsakiridis K, Teschler H, Yarmus L, Zarogoulidis $\mathrm{K}$, et al. Learning from the Cardiologists and Developing Eluting Stents Targeting the Mtor Pathway for Pulmonary Application; A Future Concept for Tracheal Stenosis. Journal of molecular and genetic medicine : an international journal of biomedical research. 2013; 7: 65. doi:10.4172/1747-0862.1000065.

35. Zarogoulidis P, Darwiche K, Walter R, Li Q, Teschler H, Freitag L, et al. Research spotlight: sirolimus-coated stents for airway tracheal stenosis: a future 3D model concept with today's knowledge. Therapeutic delivery. 2013; 4: 1093-7. doi:10.4155/tde.13.86

36. Zarogoulidis K, Zarogoulidis P, Darwiche K, Boutsikou E, Machairiotis N, Tsakiridis $\mathrm{K}$, et al. Treatment of non-small cell lung cancer (NSCLC). Journal of thoracic disease. 2013; 5 (Suppl 4): S389-96. doi:10.3978/j.issn.2072-1439.2013.07.10. 